\title{
High Incidence of Subclinical Peripheral Neuropathy in Myelitis with HyperIgEaemia and Mite Antigen-specific IgE (Atopic Myelitis): an Electrophysiological Study
}

\author{
Manabu Osoegawa, Hirofumi OchI, Takeshi Yamada, Izumi Horiuchi, Hiroyuki Murai, \\ Hirokazu Furuya, Shozo Tobimatsu* and Jun-ichi KIRA
}

\begin{abstract}
Objective To study subclinical involvement of the peripheral nerves in myelitis with hyperIgEaemia and mite antigen-specific IgE (atopic myelitis: AM).

Material and Methods We carried out a nerve conduction study of the median, ulnar, tibial, and sural nerves in 21 patients with $\mathrm{AM}$ and in 28 patients with clinically definite or laboratory-supported definite multiple sclerosis (MS).

Results The patients with AM showed a significantly higher frequency of abnormal records than the MS patients in the sensory nerve conduction study $(52.4 \%$ vs. $14.3 \%$, $p=0.0106)$. The frequency of abnormal records in the motor nerve conduction study in AM patients was twice as high as in MS patients (38.1\% vs. $17.9 \%)$, but the difference was not statistically significant. Abnormality in the Fwave-evoked frequency in the median nerve was also significantly more common in AM patients than in MS patients $(57.9 \%$ vs. $10.7 \%$, $p=0.0016)$.

Conclusions These findings suggest that subclinical peripheral neuropathy is frequent in patients with $A M$. (Internal Medicine 41: 684-691, 2002)

Key words: myelitis with hyperIgEaemia, atopic dermatitis, multiple sclerosis, axonal neuropathy, compression neuropathy, demyelinating neuropathy, nerve conduction study
\end{abstract}

\section{Introduction}

Atopy is characterized by enhanced IgE responses to such common environmental antigens as pollens, foods and housedust mites (1). Although atopy had not previously been shown to be associated with myelitis, we recently reported occurrences of localized myelitis in patients with hyperIgEaemia and mite antigen-specific IgE and named it atopic myelitis (AM) (2-4). In addition, AM was recently shown to exhibit spinal cord inflammation with eosinophil infiltration (5). Because eosinophil infiltration is commonly seen in such atopic disorders as atopic dermatitis (AD) (6), atopic bronchial asthma (7) and allergic rhinitis (8), the eosinophilic inflammation of the spinal cord in AM patients may suggest an allergic mechanism to be operative even in the central nervous system (CNS).

On the other hand, we recently reported that both the serum total IgE level and the frequency of IgE specific to mite antigens were significantly higher in patients with mononeuritis multiplex (MNM) of unknown etiology than in the healthy controls (9). It is thus possible that the development of MNM may in part relate to the atopic backgrounds.

These observations prompted us to study the subclinical involvement of the peripheral nerves in AM patients who showed overt CNS lesions by either magnetic resonance imaging (MRI) or evoked potentials (EPs) in order to clarify the possibility that allergic inflammation may multifocally involve the peripheral nervous system (PNS) as well as the CNS.

\section{Materials and Methods}

\section{Subjects}

The subjects consisted of 21 patients with AM (2-4), 28 patients with either clinically definite or laboratory-supported definite MS according to the criteria of Poser et al (10) and 16 healthy controls (HC). The demographic characteristics of these patients are summarized in Table 1. AM was diagnosed as described previously (2-4), based on such criteria as the presence of hyperIgEaemia, mite antigen-specific IgE and myelitis of unknown etiology, regardless of the presence or absence of atopic dermatitis (AD). All AM patients had abnormalities indicating CNS lesions by either motor evoked potential (MEP), somatosensory evoked potential (SEP) or MRI, and the spinal cord lesions thus indicated by neurological and laboratory find-

From Departments of Neurology and *Clinical Neurophysiology, Neurological Institute, Graduate School of Medical Sciences, Kyushu University, Fukuoka Received for publication October 24, 2001; Accepted for publication; April 22, 2002

Reprint requests should be addressed to Dr. Manabu Osoegawa, Department of Neurology, Neurological Institute, Graduate School of Medicines, Kyushu University, 3-1-1 Maida-shi, Higashi-ku, Fukuoka 812-8582 
ings are shown in Table 1. The MRI lesions observed were compatible with myelitis in all AM patients enrolled in the present study. In addition, all AM patients who had abnormalities indicating CNS lesions only on evoked potentials showed improvement with immunological treatments such as corticosteroid administration, intravenous administration of immunoglobulins and plasma exchange, and were thus diagnosed as having myelitis. AM patients were 13 men and 8 women, whose age was $35.8 \pm 10.7$ years (mean $\pm S D$ ). Nine of them had AD while the other 12 did not. None of the AM patients exhibited any apparent dry symptoms. In addition, none of them had any autoantibodies, except for one patient with anti-nuclear antibody of low titers. The MS patients were 7 men and 21 women, whose age was $43.1 \pm 13.6$ years (mean $\pm S D$ ); 22 had a relaps- ing-remitting course and 6 had a chronic progressive course (2 primarily progressive, 4 secondarily progressive) (Table 2 ). The severity of neurological impairment was quantified using Kurtzke's Expanded Disability Status Scale (EDSS) (11). The EDSS scores were $3.1 \pm 0.9$ (mean \pm SD) in patients with AM and 5.1 $\pm 2.2($ mean $\pm \mathrm{SD})$ in patients with MS. The EDSS scores were significantly higher in MS than in AM $(p=0.0002)$. Since MS patients with high EDSS scores (EDSS $\geqq 6.0$ ) need a support for transfer and tend to develop mechanical nerve compression, MS patients were divided by EDSS scores into high (EDSS $\geqq 6.0$ ) and low (EDSS $\leqq 5.5$ ) severity groups (12). The EDSS scores in the high severity group (12 patients) were $7.4 \pm 0.4$ (mean $\pm \mathrm{SD}$ ), and those of the low severity group (16 patients) were $3.4 \pm 0.9$ (mean \pm SD). The EDSS scores did not

Table 1. Clinical Findings in Patients with Atopic Myelitis

\begin{tabular}{|c|c|c|c|c|c|c|c|c|c|c|c|c|c|}
\hline & \multirow[b]{2}{*}{ Age } & \multirow[b]{2}{*}{ Sex } & \multirow[b]{2}{*}{$\mathrm{AD}$} & \multirow{2}{*}{$\begin{array}{c}\text { Clinically } \\
\text { estimated } \\
\text { lesion }\end{array}$} & \multicolumn{2}{|c|}{$\begin{array}{c}\text { Central } \\
\text { abnormalities }\end{array}$} & \multicolumn{2}{|c|}{$\begin{array}{c}\text { Peripheral } \\
\text { abnormalities }\end{array}$} & \multirow{2}{*}{$\begin{array}{l}\text { Spinal } \\
\text { MRI } \\
\text { lesion }\end{array}$} & \multirow[b]{2}{*}{ EDSS } & \multicolumn{2}{|c|}{ CSF } & \multirow[b]{2}{*}{ Hyperreflexia } \\
\hline & & & & & MEP & SEP & MEP & SEP & & & Cell & $\mathrm{TP}$ & \\
\hline 1 & 30 & $\mathbf{M}$ & + & $\mathrm{C}$ & - & + & $\mathrm{N}$ & $\mathrm{N}$ & $\mathrm{N}$ & 3.0 & 2 & 70 & + \\
\hline 2 & 39 & $\mathbf{M}$ & + & $\mathrm{C}$ & - & + & $\mathrm{N}$ & $\mathrm{N}$ & $\mathrm{C} 4$ & 2.0 & 4 & 30 & + \\
\hline 3 & 41 & $\mathbf{M}$ & - & $\mathrm{C}$ & + & - & $\mathrm{N}$ & $\mathrm{N}$ & $\mathrm{N}$ & 3.0 & 1 & 30 & + \\
\hline 4 & 21 & $\mathbf{M}$ & - & $\mathrm{C}$ & + & - & $\mathrm{N}$ & $\mathrm{N}$ & C3-5 & 3.5 & 0 & 25 & - \\
\hline 5 & 42 & $\mathbf{M}$ & + & $\mathrm{C}$ & + & - & $\mathrm{N}$ & $\mathrm{N}$ & C5-6 & 3.0 & 2 & 51 & + \\
\hline 6 & 20 & $\mathrm{~F}$ & + & $\mathrm{C}$ & - & + & $\mathrm{N}$ & $\mathrm{N}$ & $\mathrm{C} 4$ & 2.0 & 2 & 25 & + \\
\hline 7 & 52 & $\mathrm{~F}$ & + & $\mathrm{C}$ & - & + & $\mathrm{N}$ & $\mathrm{N}$ & $\mathrm{C} 3$ & 3.0 & 1 & 31 & + \\
\hline 8 & 29 & $\mathrm{M}$ & + & $\mathrm{C}$ & ND & ND & ND & ND & C3-6 & 3.0 & ND & ND & + \\
\hline 9 & 38 & $\mathrm{M}$ & - & $\mathrm{C}$ & - & ND & $\mathrm{N}$ & ND & $\mathrm{C} 2-3$ & 2.0 & 2 & 30 & + \\
\hline 10 & 20 & $\mathrm{~F}$ & + & $\mathrm{C}$ & - & - & $\mathrm{N}$ & $\mathrm{N}$ & $\mathrm{C} 3-5$ & 5.0 & 1 & 52 & + \\
\hline 11 & 36 & $\mathrm{M}$ & - & $\mathrm{C}$ & + & + & U, L & U & $\mathrm{Cl}-2$ & 3.5 & 19 & 37 & + \\
\hline 12 & 48 & $\mathrm{M}$ & - & $\mathrm{Th}$ & - & + & U, L & $\mathrm{N}$ & $\mathrm{N}$ & 3.5 & 6 & 106 & - \\
\hline 13 & 35 & $\mathrm{~F}$ & - & $\mathrm{C}$ & - & + & $\mathrm{N}$ & $\mathrm{N}$ & $\mathrm{C} 4$ & 3.0 & 2 & 59 & - \\
\hline 14 & 36 & $\mathrm{M}$ & - & $\mathrm{C}$ & - & - & $\mathrm{N}$ & $\mathrm{N}$ & C6 & 3.5 & 0 & 37 & - \\
\hline 15 & 26 & $\mathrm{~F}$ & + & $\mathrm{C}$ & + & ND & $\mathrm{N}$ & ND & $\mathrm{N}$ & 3.0 & 1 & 17 & + \\
\hline 16 & 42 & $\mathrm{M}$ & + & $\mathrm{C}$ & - & + & $\mathrm{N}$ & $\mathrm{N}$ & C3-7 & 2.0 & 1 & 53 & + \\
\hline 17 & 41 & $\mathrm{~F}$ & - & $\mathrm{C}$ & - & + & $\mathrm{N}$ & $\mathrm{N}$ & C3-4 & 3.0 & 2 & 28 & - \\
\hline 18 & 29 & $\mathbf{M}$ & - & C-Th & - & + & $\mathrm{N}$ & $\mathrm{N}$ & C1-Th9 & 5.5 & 0 & 33 & + \\
\hline 19 & 22 & $\mathrm{~F}$ & - & $\mathrm{C}$ & - & + & $\mathrm{N}$ & $\mathrm{N}$ & C3-4 & 2.0 & 1 & 24 & + \\
\hline 20 & 58 & $\mathrm{~F}$ & - & $\mathrm{C}$ & + & + & $\mathrm{N}$ & $\mathrm{N}$ & $\mathrm{C} 3$ & 3.5 & 1 & 16 & - \\
\hline 21 & 47 & $\mathrm{M}$ & - & $\mathrm{Th}$ & - & + & $\mathrm{N}$ & $\mathrm{N}$ & Th2-4 & 2.5 & 0 & 29 & + \\
\hline
\end{tabular}

M: male, F: female, AD: the existence of atopic dermatitis, MEP: motor evoked potential, SEP: sensory evoked potential, EDSS: Expanded Disability Status Scale at the peak of illness, CSF: cerebral spinal fluid, TP: total protein, C: cervical lesion, Th: thoracic lesion, U: peripheral abnormalities in upper limbs, L: peripheral abnormalities in lower limbs, ND: not done, N: normal, Shadow +: abnormal results, -: normal results. Normal values (MEPs); upper limb MEPs ( $\mathrm{n}=48$, aged from 19 to 75 ): hand motor area stimulation (mean $\pm \mathrm{SD}=21.84 \pm 0.96 \mathrm{~ms}$ ), cervical root stimulation ( $13.23 \pm 0.75 \mathrm{~ms}$ ), Erb stimulation (11.45 $\pm 0.72 \mathrm{~ms})$, central conduction time (8.61 $\pm 0.69 \mathrm{~ms})$ lower limb MEPs $(\mathrm{n}=48$, aged from 19 to 75$)$ : leg motor area stimulation (mean $\pm \mathrm{SD}=39.15 \pm 1.64 \mathrm{~ms}$ ), lumbar root stimulation $(22.21 \pm 1.35 \mathrm{~ms})$, central conduction time (16.94 \pm 1.37 ms). Normal values (SEPs); upper limb SEPs ( $n=15$, aged from 14 to 55): Erb's point (N9) component (mean \pm SD=9.29 \pm 0.58 $\mathrm{ms}$ ), C7 cervical spine (N13) component $(12.67 \pm 0.79 \mathrm{~ms}), \mathrm{C} 3$ or C4 (N20) component (18.63 $\pm 0.94 \mathrm{~ms}), \mathrm{N} 13-\mathrm{N} 20 \mathrm{compo}-$ nent (5.89 $\pm 0.48 \mathrm{~ms}$ ). lower limb SEPs ( $\mathrm{n}=15$, aged from 14 to 55): Th12 (N20) component (mean $\pm \mathrm{SD}=20.02 \pm 1.45 \mathrm{~ms}$ ), $\mathrm{Cz}$ ' (P37). component (36.91 $\pm 2.48 \mathrm{~ms})$, N20-P37 component $(16.88 \pm 1.65 \mathrm{~ms})$. 
Osoegawa et al

Table 2. Clinical and Electrophysiological Findings in Patients with Multiple Sclerosis

\begin{tabular}{|c|c|c|c|c|c|c|c|c|c|c|c|}
\hline & \multirow[b]{3}{*}{ Age } & \multirow[b]{3}{*}{ Sex } & \multirow[b]{3}{*}{ EDSS } & \multirow{3}{*}{$\begin{array}{c}\text { Clinica } \\
\text { type }\end{array}$} & \multirow{3}{*}{$\begin{array}{l}\mathrm{RR} / \\
\mathrm{PR} / \\
\mathrm{SR}\end{array}$} & \multicolumn{3}{|c|}{ Motor } & \multicolumn{2}{|c|}{ Sensory } & \multirow[b]{3}{*}{ Pattern } \\
\hline & & & & & & \multirow{2}{*}{$\frac{\text { Median }}{\text { CMAP }}$} & \multicolumn{2}{|c|}{ Tibial } & \multirow{2}{*}{$\frac{\text { Median }}{\mathrm{SCV}}$} & \multirow{2}{*}{$\frac{\text { Sural }}{\mathrm{NE}}$} & \\
\hline & & & & & & & $\mathrm{MCV}$ & $\mathrm{NE}$ & & & \\
\hline 1 & 56 & $\mathrm{~F}$ & 7.5 & OS-MS & $\mathrm{RR}$ & 4 & NA & + & ND & + & axona \\
\hline 2 & 52 & $\mathrm{~F}$ & 7.5 & OS-MS & $\mathrm{RR}$ & - & - & - & - & + & axonal, possible \\
\hline 3 & 47 & $\mathrm{~F}$ & 8.5 & OS-MS & $\mathrm{RR}$ & +1 & - & - & - & t. & axonal, possible \\
\hline 4 & 49 & $\mathrm{~F}$ & 7.0 & C-MS & PP & + & - & - & - & - & compression neuropathy (carpal tunnel syndrome), possible \\
\hline 5 & 36 & $\mathrm{~F}$ & 7.5 & C-MS & $\mathrm{RR}$ & +3 & - & - & + & - & compression neuropathy (carpal tunnel syndrome), possible \\
\hline 6 & 63 & $\mathrm{~F}$ & 7.0 & OS-MS & $\mathrm{RR}$ & - & + & - & - & - & demyelinating, possible \\
\hline 7 & 33 & F & 7.0 & C-MS & RR & - & - & - & - & - & normal \\
\hline 8 & 51 & $\mathrm{~F}$ & 7.0 & OS-MS & $\mathrm{RR}$ & - & - & - & - & - & normal \\
\hline 9 & 64 & $\mathrm{~F}$ & 7.5 & OS-MS & $\mathrm{RR}$ & - & - & - & - & - & normal \\
\hline 10 & 49 & $\mathrm{~F}$ & 7.5 & C-MS & $\mathrm{RR}$ & - & - & - & - & - & normal \\
\hline 11 & 49 & $\mathrm{~F}$ & 7.5 & C-MS & SP & - & - & - & - & - & normal \\
\hline 12 & 63 & $\mathbf{M}$ & 7.5 & C-MS & PP & - & - & - & - & - & normal \\
\hline 13 & 30 & M & 2.0 & C-MS & $R R$ & - & - & - & - & - & normal \\
\hline 14 & 29 & $\mathbf{M}$ & 2.0 & C-MS & $\mathrm{RR}$ & - & - & - & - & - & normal \\
\hline 15 & 36 & $\mathrm{~F}$ & 2.5 & OS-MS & $\mathrm{RR}$ & - & - & - & - & - & normal \\
\hline 16 & 21 & $\mathrm{~F}$ & 3.0 & OS-MS & $\mathrm{RR}$ & - & - & - & - & - & normal \\
\hline 17 & 49 & $\mathrm{~F}$ & 3.0 & OS-MS & $\mathrm{RR}$ & - & - & - & - & - & normal \\
\hline 18 & 34 & $\mathbf{M}$ & 3.0 & C-MS & $\mathrm{RR}$ & - & - & - & - & - & normal \\
\hline 19 & 33 & M & 3.0 & C-MS & RR & - & - & - & - & - & normal \\
\hline 20 & 30 & $\mathrm{~F}$ & 3.5 & OS-MS & $\mathrm{RR}$ & - & - & - & - & - & normal \\
\hline 21 & 67 & $\mathrm{~F}$ & 3.5 & OS-MS & $\mathrm{RR}$ & - & - & - & - & - & normal \\
\hline 22 & 24 & $\mathrm{~F}$ & 3.5 & C-MS & $\mathrm{RR}$ & - & - & - & - & - & normal \\
\hline 23 & 54 & $\mathrm{~F}$ & 3.5 & C-MS & $\mathrm{RR}$ & - & - & - & - & - & normal \\
\hline 24 & 52 & $\mathrm{~F}$ & 3.5 & C-MS & $\mathrm{RR}$ & - & - & - & - & - & normal \\
\hline 25 & 30 & F & 3.5 & C-MS & SP & - & - & - & - & - & normal \\
\hline 26 & 24 & $\mathbf{M}$ & 4.5 & C-MS & SP & - & - & - & - & - & normal \\
\hline 27 & 51 & M & 4.5 & C-MS & $\mathrm{RR}$ & - & - & - & - & - & normal \\
\hline 28 & 32 & $\mathrm{~F}$ & 5.5 & C-MS & SP & - & - & - & - & - & normal \\
\hline
\end{tabular}

M: male, F: female, EDSS: Expanded Disability Status Scale at the peak of illness, OS-MS: optic-spinal MS, C-MS: conventional MS, RR: relapsing-remitting course, PP: primarily progressive course, SP: secondarily progressive course, MCV: motor conduction velocity, CMAP: amplitude of compound muscle action potential, SCV: sensory conduction velocity, NE: not evoked, ND: not done, NA: not appreciated. Shadow +: abnormal results, -: normal results. Normal values (nerve conduction study); median nerve $(\mathrm{n}=16$, mean $\pm \mathrm{SD}=38.8 \pm 12.4$ years): $\mathrm{MCV}($ mean $\pm \mathrm{SD}=56.8 \pm 3.7 \mathrm{~m} / \mathrm{s})$, DL $(3.8 \pm 0.3 \mathrm{~ms}), \mathrm{CMAP}(19.5 \pm 5.9 \mathrm{mV}), \mathrm{SCV}(51.3 \pm 3.8 \mathrm{~m} / \mathrm{s}), \mathrm{SNAP}(46.6 \pm 16.6 \mu \mathrm{V})$. ulnar nerve $(\mathrm{n}=6$, mean $\pm \mathrm{SD}=28.0 \pm 4.0$ years): $\mathrm{MCV}(\mathrm{mean} \pm \mathrm{SD}=64.7 \pm 3.4 \mathrm{~m} / \mathrm{s}), \mathrm{DL}(2.8 \pm 0.4 \mathrm{~ms}), \mathrm{CMAP}(15.4 \pm 2.0 \mathrm{mV}), \mathrm{SCV}(47.8 \pm 4.6 \mathrm{~m} / \mathrm{s}), \mathrm{SNAP}(47.3 \pm 10.0$ $\mu \mathrm{V})$. tibial nerve $(\mathrm{n}=16$, mean $\pm \mathrm{SD}=36.7 \pm 10.4$ years): $\mathrm{MCV}(\mathrm{mean} \pm \mathrm{SD}=46.9 \pm 3.7 \mathrm{~m} / \mathrm{s}), \mathrm{DL}(5.4 \pm 1.1 \mathrm{~ms}), \mathrm{CMAP}(15.8 \pm 6.6 \mathrm{mV})$. sural nerve $(\mathrm{n}=16$, mean $\pm \mathrm{SD}=36.7 \pm 10.4$ years $): \mathrm{SCV}(\mathrm{mean} \pm \mathrm{SD}=49.6 \pm 6.8 \mathrm{~m} / \mathrm{s}), \mathrm{SNAP}(12.0 \pm 4.0 \mu \mathrm{V})$.

differ significantly between the AM group and the low-severity MS group. None of the patients showed clinically overt signs of peripheral neuropathy. Moreover, no lesions were found in the spinal cord roots on MRI in any patient. The control subjects were 7 men and 9 women whose age was $38.9 \pm 12.4$ years (mean $\pm \mathrm{SD}$ ). Informed consent was obtained from all subjects.

\section{Electrophysiological studies}

Nerve conduction studies were performed on one upper and one lower limb using standard techniques on the median motor and sensory, tibial motor and sural sensory nerves in the three groups. In addition, nerve conduction studies on the ulnar motor and sensory nerves were performed in most AM patients. Compound muscle action potentials (CMAP) of the median nerve were recorded on the abductor pollicis brevis muscle, those of the ulnar nerves on the abductor digiti minimi muscle, and those of the tibial nerves on the abductor hallucis muscle. All latencies were measured to the onset latency of the recorded waveform. The distal onset latency was measured at the distance of $6.5 \mathrm{~cm}$ between stimulating and recording electrodes for the median nerve, at $7 \mathrm{~cm}$ for the ulnar nerve and at $10 \mathrm{~cm}$ for the tibial nerve. Motor nerve conduction velocities 
(MCV) and amplitudes of CMAP of the median, ulnar, and tibial nerves were measured in the forearm and leg, respectively. Sensory nerve conduction velocities (SCV) and amplitudes of sensory nerve action potentials (SNAP) were measured orthodromically, and the onset latencies were measured at the distances of $13 \mathrm{~cm}, 11 \mathrm{~cm}$ and $14 \mathrm{~cm}$ between stimulating and recording electrodes in the median, ulnar, and sural nerves, respectively. Peak-to-peak amplitudes were measured in CMAP and SNAP. F-wave responses were recorded with 16 consecutive stimuli at the wrist in the median nerve and at the ankle in the tibial nerve. Moreover, the F-wave of the ulnar nerve was examined in most patients with AM. The shortest latencies and the evoked frequency of F-waves were measured. All electrophysiologic recordings were done by the same examiner (M.O.) with the patient in the supine position in a semidarkened air-conditioned room keeping limb temperature at 32$34^{\circ} \mathrm{C}$. Results in the normal range were obtained from the healthy controls and defined as the mean \pm 2 SDs. Evidence of demyelination included decreased motor conduction velocity, increased distal motor nerve latency or increased minimal Fwave latency, according to previously described criteria for demyelination (13).

SEPs and MEPs in upper and lower limbs were recorded as described previously (14). In brief, the peak latencies of N9 (Erb's point), N13 (C7 cervical spine) and N20 (C3 or C4) were measured for the median SEPs. For the tibial SEPs, the peak latencies of $\mathrm{N} 20$ (Th12 thoracic spine) and P37 (Cz') were measured. The upper limb (UL) MEPs were recorded from the abductor pollicis brevis muscle by stimulating the hand motor area, cervical roots and Erb's point with a figure 8-shaped magnetic coil. The lower limbs (LL) MEPs were recorded from the abductor hallucis muscle by stimulating leg motor area and lumbar roots. EPs were classified as abnormal if the latencies and the central conduction time were delayed more than 3 SDs above the normal data or if any component was absent. In particular, peripheral abnormalities in MEPs were considered if the latencies were delayed more than 3 SDs above the normal data or if any component was absent on the cervical or lumbar root stimulation, while in SEPs peripheral abnormalities were considered if N9 latency was delayed more than 3 SDs above normal data or if $\mathrm{N} 9$ component was absent in UL.

\section{Statistical analysis}

Statistical analyses of the frequency of abnormal records were done by the chi-square test, or Fisher's exact test when the criteria for the chi-square test were not fulfilled.

\section{Results}

\section{Nerve conduction study}

The AM patients had a significantly higher frequency of total abnormal records in the sensory nerves than the MS patients $(52.4 \%$ vs. $14.3 \%$ ) (Tables 3,4$)$. The AM patients had a significantly higher frequency of abnormal records than the MS patients in the median nerve $(55.0 \%$ vs. $3.7 \%, \mathrm{p}<0.0001)$ but not in the sural nerve (31.3\% vs. $10.7 \%$ ) (Tables 3,4$)$. The abnormal frequency was significantly higher in each parameter in the AM group than in the MS group in SNAP (50.0\% vs. $0.0 \%, \mathrm{p}<0.0001$ ) but not in SCV and the frequency of unevoked records. Among MS patients with low EDSS scores, none was abnormal in any parameter in either nerve.

The frequency of total abnormal records in the motor nerve conduction study in AM patients was twice as high as in MS patients, but the difference was not statistically significant (38.1\% vs. $17.9 \%$ ) (Tables 3,5 ). When AM patients were compared with MS patients with low EDSS scores $(\leqq 5.5)$, the former had a significantly higher frequency of abnormal records than the latter in the motor nerves ( $38.1 \%$ vs. $0.0 \%, \mathrm{p}=0.0056)$. When the frequency of abnormal records was compared between the median and the tibial nerves in AM patients, the frequency of abnormal records tended to be higher in the median nerve than in the tibial nerve ( $33.3 \%$ vs. $5.9 \%, \mathrm{p}=0.0534)$. The frequency of MCV, CMAP and conduction block were not significantly different between the AM and MS groups in any parameter, whereas the distal latencies were more frequently prolonged in the AM patients than in the MS patients (23.8\% vs. $0.0 \%, \mathrm{p}=0.0107$ ) in the median nerve.

Based on the results of motor and sensory nerve conduction studies, the frequency of subclinical peripheral nerve involvement was significantly higher in the AM patients than in all MS patients $(57.1 \%$ vs. $21.4 \%, \mathrm{p}=0.0230)$ and MS patients with low EDSS scores (57.1\% vs. $0.0 \%, \mathrm{p}=0.0009$ ). In MS, the high EDSS score group showed a significantly higher frequency of subclinical peripheral nerve involvement than the low EDSS score group (50.0\% vs. $0 \%, \mathrm{p}=0.0025)$. In AM patients, the frequency of subclinical involvement was higher in the upper limbs (the median nerve: 12 of 21, 57.1\%) than in the lower limbs (the tibial nerve and the sural nerve: 6 of 17,35.3\%), but the difference was not statistically significant. In AM patients, the frequency of subclinical involvement was not significantly higher in the median nerve (12 of $21,57.1 \%)$ than in the ulnar nerve (8 of $17,47.1 \%)$.

\section{F-wave conduction study}

Minimal F-wave latency in the median nerve was normal in both AM patients and MS patients, while it was normal in all but two patients (patient 12 with AM and one with MS) in the tibial nerve (Table 6). Abnormality in the F-wave-evoked frequency in the median nerve was significantly more common in AM patients than in all MS patients $(57.9 \%$ vs. $10.7 \%$, $\mathrm{p}=0.0016)$ and those with low EDSS scores (57.9\% vs. $12.5 \%$, $\mathrm{p}=0.0152$ ), while it was not significantly different between AM patients and MS patients in the tibial nerve.

\section{Peripheral abnormalities in SEPs or MEPS}

MEP was abnormal for peripheral nerves in two of $21 \mathrm{AM}$ patients (Table 1). A prolonged latency was observed for the peripheral nerves of the upper and lower limbs in patients 11 and 12. Prolonged latency in SEP was observed (N9) in patient 11 . On the contrary, no peripheral abnormality was found in either MEP or SEP in any MS patient examined (MEP: 22 examined, SEP: 21 examined). 
Table 3. Electrophysiological Findings of the Peripheral Nerves in Patients with Atopic Myelitis

\begin{tabular}{|c|c|c|c|c|c|c|c|c|c|c|c|c|c|c|c|c|c|}
\hline & \multicolumn{8}{|c|}{ Motor } & \multicolumn{8}{|c|}{ Sensory } & \multirow[b]{3}{*}{ Pattern } \\
\hline & \multicolumn{5}{|c|}{ Median } & \multirow{2}{*}{$\begin{array}{l}\text { Ulnar } \\
\text { total }\end{array}$} & \multicolumn{2}{|c|}{ Tibial } & \multicolumn{2}{|c|}{ Median } & \multicolumn{3}{|c|}{ Ulnar } & \multicolumn{3}{|c|}{ Sural } & \\
\hline & MCV & BLOCK & DL & CMAP & FL & & $\mathrm{DL}$ & FL & SCV & SNAP & SCV & SNAP & $\mathrm{NE}$ & SCV & SNAP & $\mathrm{NE}$ & \\
\hline 1 & - & - & - & - & - & - & - & - & - & + & - & + & - & - & + & - & axonal \\
\hline 2 & - & - & - & - & ND & - & - & ND & - & + & - & + & - & - & + & - & axonal \\
\hline 3 & - & - & - & - & - & - & - & - & - & + & - & + & - & - & + & - & axonal \\
\hline 4 & - & - & 4 & - & + & - & - & - & - & + & - & - & - & - & + & - & axonal, possible, in addition to carpal tunnel syndrome \\
\hline 5 & - & - & + & - & - & - & - & - & - & + & - & + & - & - & - & - & axonal or compression neuropathy \\
\hline 6 & - & - & - & - & - & - & ND & ND & t. & t: & t. & 1. & - & ND & ND & ND & axonal or compression neuropathy \\
\hline 7 & - & - & t & - & - & - & - & - & + & t. & NA & NA & + & - & - & - & axonal or compression neuropathy \\
\hline 8 & - & - & + & - & ND & ND & ND & ND & + & + & ND & ND & ND & ND & ND & ND & axonal or compression neuropathy (carpal tunnel syndrome), possible \\
\hline 9 & - & - & - & + & - & - & - & - & - & 1. & - & - & - & - & - & - & compression neuropathy (carpal tunnel syndrome), possible \\
\hline 10 & - & - & - & - & - & - & + & - & + & + & + & - & - & - & - & - & demyelinating, possible \\
\hline 11 & + & + & - & t. & - & - & - & - & - & - & ND & ND & ND & - & - & - & demyelinating, possible \\
\hline 12 & + & + & + & - & - & - & - & + & + & - & + & + & - & NA & NA & + & demyelinating, possible \\
\hline 13 & - & - & - & - & - & - & - & - & - & - & - & - & - & - & - & - & normal \\
\hline 14 & - & - & - & - & - & - & ND & ND & - & - & - & - & - & ND & ND & ND & normal \\
\hline 15 & - & - & - & - & - & - & ND & ND & - & - & - & - & - & ND & ND & ND & normal \\
\hline 16 & - & - & - & - & - & ND & - & - & - & - & ND & ND & ND & ND & ND & $\mathrm{ND}$ & normal \\
\hline 17 & - & - & - & - & - & - & - & - & - & - & - & - & - & - & - & - & normal \\
\hline 18 & - & - & - & - & - & - & - & - & - & - & - & - & - & - & - & - & normal \\
\hline 19 & - & - & - & - & - & $\mathrm{ND}$ & - & - & - & - & ND & ND & ND & - & - & - & normal \\
\hline 20 & - & - & - & - & - & - & - & - & - & - & - & - & - & - & - & - & normal \\
\hline 21 & - & - & - & - & - & ND & - & - & ND & ND & ND & ND & ND & - & - & - & normal \\
\hline
\end{tabular}

MCV: motor conduction velocity, DL: distal latency, CMAP: amplitude of compound muscle action potential, FL: minimum F wave latency, SCV: sensory conduction velocity, SNAP: amplitude of sensory nerve action potential, NE: not evoked, ND: not done, NA: not appreciated, $\mathrm{N}$ : normal, Shadow +: abnormal results, -: normal results. Normal values (nerve conduction study); median nerve $(\mathrm{n}=16$, mean $\pm \mathrm{SD}=38.8 \pm 12.4$ years): $\mathrm{MCV}($ mean $\pm \mathrm{SD}=56.8 \pm 3.7 \mathrm{~m} / \mathrm{s}), \mathrm{DL}(3.8 \pm 0.3 \mathrm{~ms}), \mathrm{CMAP}(19.5 \pm 5.9 \mathrm{mV}), \mathrm{SCV}(51.3 \pm 3.8 \mathrm{~m} / \mathrm{s}), \mathrm{SNAP}(46.6 \pm 16.6 \mu \mathrm{V})$. ulnar nerve $(\mathrm{n}=6$, mean $\pm \mathrm{SD}=28.0 \pm 4.0$ years $): \mathrm{MCV}$ (mean $\pm \mathrm{SD}=64.7 \pm 3.4 \mathrm{~m} / \mathrm{s}), \mathrm{DL}(2.8 \pm 0.4 \mathrm{~ms}), \mathrm{CMAP}(15.4 \pm 2.0 \mathrm{mV}), \mathrm{SCV}(47.8 \pm 4.6 \mathrm{~m} / \mathrm{s}), \mathrm{SNAP}$ $(47.3 \pm 10.0 \mu \mathrm{V})$. tibial nerve $(\mathrm{n}=16$, mean $\pm \mathrm{SD}=36.7 \pm 10.4$ years $)$ : MCV (mean $\pm \mathrm{SD}=46.9 \pm 3.7 \mathrm{~m} / \mathrm{s}), \mathrm{DL}(5.4 \pm 1.1 \mathrm{~ms}), \mathrm{CMAP}(15.8 \pm 6.6 \mathrm{mV})$. sural nerve $(\mathrm{n}=16$, mean $\pm \mathrm{SD}=36.7 \pm 10.4$ years): $\mathrm{SCV}$ (mean $\pm \mathrm{SD}=49.6 \pm 6.8 \mathrm{~m} / \mathrm{s}), \mathrm{SNAP}(12.0 \pm 4.0 \mu \mathrm{V})$. Normal values $(\mathrm{F}-\mathrm{wave}$ study); median $(n=16$, mean $\pm \mathrm{SD}=38.8 \pm 12.4$ years): latency (mean $\pm \mathrm{SD}=24.8 \pm 1.9 \mathrm{~ms})$, frequency $(88.8 \pm 8.4 \%)$. ulanr $(\mathrm{n}=6, \mathrm{mean} \pm \mathrm{SD}=28.0 \pm 4.0$ years): latency (mean $\pm \mathrm{SD}=23.0 \pm 1.3 \mathrm{~ms})$, frequency $(93.8 \pm 7.9 \%)$, tibial $(\mathrm{n}=16$, mean $\pm \mathrm{SD}=36.7 \pm 10.4$ years): latency $(\mathrm{mean} \pm \mathrm{SD}=46.5 \pm 4.2$ $\mathrm{ms})$, frequency $(96.3 \pm 5.7 \%)$.

Table 4. Frequency of Abnormal Records in Sensory Nerve Conduction Study

\begin{tabular}{|c|c|c|c|c|c|c|c|c|c|c|}
\hline & & \multirow{2}{*}{$\begin{array}{l}\text { Sensory nerves } \\
\text { total }\end{array}$} & \multicolumn{4}{|c|}{ Median nerve } & \multicolumn{4}{|c|}{ Sural nerve } \\
\hline & & & Total & $\operatorname{SCV}(\mathrm{m} / \mathrm{s})$ & SNAP $(\mu V)$ & $\mathrm{NE}$ & Total & $\mathrm{SCV}(\mathrm{m} / \mathrm{s})$ & $\operatorname{SNAP}(\mu \mathrm{V})$ & $\mathrm{NE}$ \\
\hline $\mathrm{AM}$ & abnormal (\%) & $11 / 21(52.4)^{*, 00}$ & $11 / 20(55.0)^{* *, \infty}$ & $5 / 20(25.0)$ & $10 / 20(50.0)^{* * . \Delta 0}$ & $0 / 20(0.0)$ & $5 / 16(31.3)^{\diamond}$ & $0 / 15(0.0)$ & $4 / 15(26.7)^{*, 0}$ & $1 / 16(6.3)$ \\
\hline$(n=21)$ & mean $<$ range $>$ & & \multicolumn{4}{|c|}{$49.0<32.0-72.0>17.4<1.7-61.4>$} & \multicolumn{2}{|r|}{$48.7<40.0-61.0>$} & $12.6<2.7-37.9>$ & \\
\hline MS & abnormal (\%) & $4 / 28(14.3)$ & $1 / 27(3.7)$ & $1 / 27(3.7)$ & $0 / 27(0.0)$ & $0 / 27(0.0)$ & $3 / 28(10.7)$ & $0 / 25(0.0)$ & $0 / 25(0.0)$ & $3 / 28(10.7)$ \\
\hline$(\mathrm{n}=28)$ & mean $<$ range $>$ & & \multicolumn{4}{|c|}{$51.3<42.0-58.0>43.7<16.3-98.2>$} & \multicolumn{2}{|r|}{$50.3<40.0-67.0>$} & \multicolumn{2}{|l|}{$18.1<7.6-46.8>$} \\
\hline MS (EDSS $\leqq 5.5)$ & abnormal (\%) & $0 / 16(0.0)$ & $0 / 16(0.0)$ & $0 / 16(0.0)$ & $0 / 16(0.0)$ & $0 / 16(0.0)$ & $0 / 16(0.0)$ & $0 / 16(0.0)$ & $0 / 16(0.0)$ & $0 / 16(0.0)$ \\
\hline$(n=16)$ & mean $<$ range $>$ & & \multicolumn{4}{|c|}{$53.1<45.0-58.0>46.5<16.3-89.1>$} & \multicolumn{2}{|r|}{$52.5<42.0-67.0>$} & $19.2<8.5-46.8>$ & \\
\hline Normal limits & & & & $\geqq 43.0$ & $\geqq 14.0$ & & & $\geqq 36.0$ & $\geqq 4.0$ & \\
\hline
\end{tabular}

( ): abnormal percentage, AM: atopic myelitis, MS: multiple sclerosis, SCV: sensory conduction velocity, SNAP: amplitude of sensory nerve action potential, NE: not evoked, EDSS: Expanded Disability Status Scale at the peak of the illness. *,**: The difference was statistically significant as compared to the total MS patients $(*=\mathrm{p}<0.05, * *=\mathrm{p}<0.01) .{ }^{0,00}$. The difference was statistically significant as compared to the MS patients with low EDSS scores $\left({ }^{\circ}=\mathrm{p}<0.05,{ }^{\infty}=\mathrm{p}<0.01\right)$. 
Table 5. Frequency of Abnormal Records in Motor Nerve Conduction Study

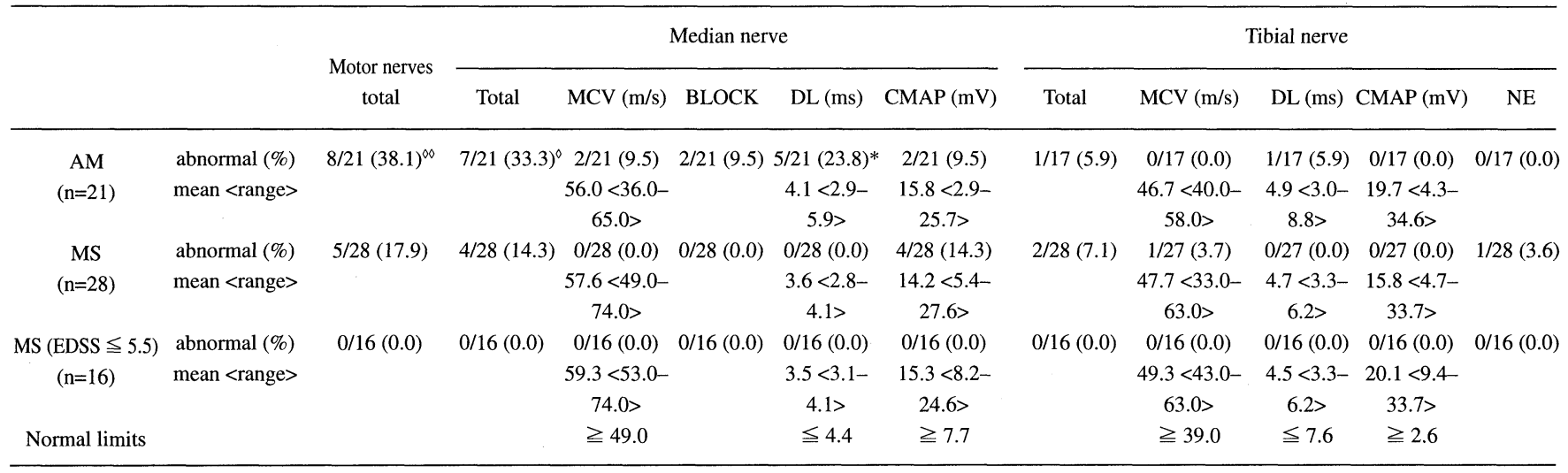

( ): abnormal percentage, AM: atopic myelitis, MS: multiple sclerosis, MCV: motor conduction velocity, DL: distal latency, CMAP: amplitude of compound muscle action potential, NE: not evoked, EDSS: Expanded Disability Status Scale at the peak of the illness. **: The difference was statistically significant as compared to the total MS patients $(* *=p<0.01) . \otimes, \infty\rangle$ : The difference was statistically significant as compared to the MS patients with low EDSS scores $\left({ }^{\circ}=\mathrm{p}<0.05,{ }^{\infty}=\mathrm{p}<0.01\right)$.

Table 6. Frequency of Abnormal Records in F-wave Conduction Study

\begin{tabular}{|c|c|c|c|c|c|c|c|c|c|c|}
\hline & & \multirow{2}{*}{$\begin{array}{c}\text { F-waves } \\
\text { total }\end{array}$} & \multicolumn{4}{|c|}{ Median nerve } & \multicolumn{4}{|c|}{ Tibial nerve } \\
\hline & & & Total & Latency (ms) & Frequency (\%) & $\mathrm{NE}$ & Total & Latency (ms) & Frequency $(\%)$ & NE \\
\hline $\begin{array}{c}\mathrm{AM} \\
(\mathrm{n}=21)\end{array}$ & mean $<$ range $>$ & & & $25.3<22.2-29.3>$ & $71.8<43-100>$ & & \multicolumn{4}{|c|}{$47.2<40.2-60.6>94.6<81-100>$} \\
\hline $\begin{array}{c}\text { MS } \\
(\mathrm{n}=28)\end{array}$ & abnormal (\%) & $8 / 28(28.6)$ & $3 / 28(10.7)$ & $0 / 28(0.0)$ & $3 / 28(10.7)$ & $0 / 28(0.0)$ & $6 / 28(21.4)$ & $1 / 28(3.6)$ & $5 / 28(17.9)$ & $0 / 28(0.0)$ \\
\hline \multirow{2}{*}{$\begin{array}{c}\mathrm{MS}(\mathrm{EDSS} \leqq 5.5) \\
(\mathrm{n}=16)\end{array}$} & abnormal (\%) & \multirow[t]{2}{*}{$4 / 16(25.0)$} & \multirow[t]{2}{*}{$2 / 16(12.5)$} & $0 / 16(0.0)$ & $2 / 16(12.5)$ & \multirow[t]{2}{*}{$0 / 16(0.0)$} & \multirow[t]{2}{*}{$2 / 16(12.5)$} & $0 / 16(0.0)$ & $2 / 16(12.5)$ & \multirow[t]{2}{*}{$0 / 16(0.0)$} \\
\hline & mean $<$ range $>$ & & & $23.8<20.4-25.7>$ & $87.4<63-100>$ & & & $45.0<39.9-48.5>$ & $92.6<81-100>$ & \\
\hline Normal limits & & & & $\leqq 28.6$ & $\geqq 73$ & & & $\leqq 54.9$ & $\geqq 84$ & \\
\hline
\end{tabular}

( ): abnormal percentage, AM: atopic myelitis, MS: multiple sclerosis, NE: not evoked, EDSS: Expanded Disability Status Scale at the peak of the illness. $* * *$ : The difference was statistically significant as compared to the total MS patients $(*=\mathrm{p}<0.05, * *=\mathrm{p}<0.01){ }^{0}:$ The difference was statistically significant as compared to the MS patients with low EDSS scores $\left({ }^{\ominus}=\mathrm{p}<0.05\right)$.

\section{Pattern of peripheral nerve involvement}

The peripheral nerve involvement in AM patients was classified into three patterns according to the electrophysiological finding: axonal neuropathy, compression neuropathy and demyelinating neuropathy (Table 3).

\section{Possible axonal neuropathy pattern}

Patients 1, 2 and 3 had reduced SNAP amplitudes in the median, ulnar and sural nerves $(6.9 \mu \mathrm{V}, 6.9 \mu \mathrm{V}, 3.0 \mu \mathrm{V}$, respectively, in patient $1 ; 13.7 \mu \mathrm{V}, 5.2 \mu \mathrm{V}, 3.1 \mu \mathrm{V}$, respectively, in patient $2 ; 1.7 \mu \mathrm{V}, 2.3 \mu \mathrm{V}, 2.9 \mu \mathrm{V}$, respectively, in patient 3 ). Patient 4 had SNAP abnormalities in the median and the sural nerves $(9.9 \mu \mathrm{V}, 2.7 \mu \mathrm{V})$ and prolonged distal latency in the median nerve $(5.0 \mathrm{~ms})$.

\section{Possible compression neuropathy pattern}

Patients 8 and 9 had abnormalities only in the median nerve showing prolonged distal latency ( $5.9 \mathrm{~ms}$ in patient 8 ) or reduced CMAP (2.94 mV in patient 9) and reduced SNAP in both $(12.0 \mu \mathrm{V}$ and $12.2 \mu \mathrm{V}$, respectively) with reduced $\mathrm{CV}$ in one $(33 \mathrm{~m} / \mathrm{s}$ in patient 8$)$. Moreover, patients 5,6 and 7 had SNAP abnormalities in the median as well as the ulnar nerves (in the median and ulnar nerves, $7.7 \mu \mathrm{V}$ and $4.5 \mu \mathrm{V}$, respectively, in patient $5 ; 7.8 \mu \mathrm{V}$ and $5.8 \mu \mathrm{V}$, respectively, in patient $6 ; 5.2 \mu \mathrm{V}$ and not evoked, respectively, in patient 7), and distal latency of the median motor nerve was also prolonged in two of them $(5.0 \mathrm{~ms}$ in patient 5 and $5.2 \mathrm{~ms}$ in patient 7$)$.

\section{Demyelinating neuropathy pattern}

Patient 10 showed a delay of distal latency ( $8.8 \mathrm{~ms}:>125 \%$ of upper limit of normal distal latency with normal amplitude) in the tibial nerve together with a reduction of SCV in the median and the ulnar nerves. In patient 11 , in addition to conduction block and reduced MCV (36 m/s: $<80 \%$ of lower limit of 
normal with amplitude $>80 \%$ of lower limit of normal) in the median nerve, MEP showed peripheral conduction abnormalities in the upper and lower limbs and SEP showed peripheral conduction abnormalities in the upper limbs. In patient 12, in addition to conduction block and prolonged distal latency (5.5 ms: $>125 \%$ of upper limit of normal distal latency with normal amplitude) and reduced sensory CV (34 m/s: $<80 \%$ of lower limit of normal with amplitude $>80 \%$ of lower limit of normal) in the median nerve, sensory nerve action potential was not evoked in the sural nerve and minimal $F$ wave latency was prolonged in the tibial nerve. Patient 12 also showed peripheral conduction abnormalities in the upper limb MEPs.

\section{Comparison of neuropathy pattern between atopic myelitis and multiple sclerosis}

In the six MS patients showing abnormality in nerve conduction, subclinical axonal neuropathy was diagnosed in three, possible demyelinating neuropathy in one and carpal tunnel syndrome in two (Table 2). In MS, while 6 of 12 patients having EDSS scores higher than 6.0 showed subclinical peripheral neuropathy, none of the 16 patients having EDSS scores lower than 6.0 had subclinical neuropathy (50\% vs. $0 \%$, $\mathrm{p}=0.0025$ ). Although the frequency of possible subclinical compression neuropathy in AM patients (5 of 21, 23.8\%) was not significantly higher than in total MS patients ( 2 of $28,7.1 \%$ ), it tended to be higher than in MS patients with lower EDSS scores $(0$ of $16,0 \%)(\mathrm{p}=0.0567)$.

\section{Comparison of frequency of subclinical peripheral neuropa- thy in AM patients with or without atopic dermatitis}

The frequency of subclinical peripheral neuropathy was higher in AM patients with atopic dermatitis (7 of 9, 77.8\%) than in AM patients without atopic dermatitis (5 of 12, 41.7\%), but the difference was not statistically significant due to the small sample size.

\section{Discussion}

This study has shown for the first time that subclinical PNS involvement frequently occurs in AM patients who have overt CNS lesions. In the present study, we compared the frequency of PNS involvement in AM patients with those in MS patients. MS is considered to be an autoimmune disease targeting only the CNS myelin. However, PNS involvement in MS has been reported to be $11-35 \%(12,15,16)$. In MS, patients with severe disability are prone to develop mechanical compression of the peripheral nerves, which in part accounts for the PNS involvement. In our study, none of MS patients having EDSS scores lower than 6.0 showed any subclinical involvement of the PNS. On the contrary, the AM patients showed a high frequency of PNS involvement, yet all of them had relatively low EDSS scores (less than 6.0). This observation suggests that some distinct mechanism other than the autoimmune attacks on the CNS myelin seen in MS may be operative in AM.

Three patterns of neuropathy were observed in AM patients: axonal neuropathy, compression neuropathy and demyelinat- ing neuropathy. Because patients 1, 2 and 3 had reduced SNAP amplitudes in the all the nerves examined, they were thus considered to have subclinical axonal neuropathy involving upper and lower limb sensory nerves. Patient 4 , who had reduced SNAP amplitude in the sural nerve in addition to localized conduction abnormalities across the wrist in the median nerve, was considered to have possible axonal neuropathy in addition to carpal tunnel syndrome. Because patients 5, 6 and 7 had localized conduction abnormalities across the wrist, they were considered to have possible compression neuropathy, such as carpal tunnel syndrome or Guyon canal syndrome. Patients 8 and 9 had abnormalities only in the median nerve, so they were likely to have carpal tunnel syndrome. Patient 10 showed a delay of distal latency in the tibial nerve together with a reduction of SCV in the median and ulnar nerves, and thus she was considered to have a possible demyelinating pattern electrophysiologically. As for patient 11, in addition to conduction block and reduced MCV in the median nerve, MEP showed peripheral conduction abnormalities in the upper and lower limbs and SEP showed peripheral conduction abnormalities in the upper limbs, so he was considered to have a possible demyelinating pattern electrophysiologically. In patient 12 , in addition to conduction block, prolonged distal latency and reduced sensory CV in the median nerve, SNAP was not evoked in the sural nerve, minimal $\mathrm{F}$ latency was prolonged in the tibial nerve and MEP showed peripheral conduction abnormalities in the upper limbs, and he was thus considered to have a possible demyelinating neuropathy pattern electrophysiologically.

The peripheral nerves appeared to be more vulnerable to local compression in AM patients, especially in those with $\mathrm{AD}$, than in MS patients. In the AD skin, mast cells, which are in an activated state and increased numbers (17), initiate the acute inflammation through the release of vasoactive amines and cytokines on activation by IgE-mediated mechanisms. On the other hand, mast cells are also known to be triggered by mechanical stimuli (17). Therefore, increased vascular permeability triggered by activated mast cells may tend to occur around the wrist and contribute to the development of compression neuropathy in adult patients with $\mathrm{AD}$, who are prone to have skin lesions in the upper half body and frequently scratch the itchy skin (1). The enhanced vulnerability of the peripheral nerves to local compression may well explain the higher frequency of subclinical neuropathy in the upper limbs than in the lower limbs in AM patients.

Axonal neuropathy affecting multiple peripheral nerves in the upper and lower limbs was also observed in several patients with AM. Churg-Strauss syndrome is a well-known syndrome associated with atopic disorders in which atopic bronchial asthma precedes the development of MNM. In this condition, eosinophilic infiltration as well as deposition of $\operatorname{IgE}$ in the peripheral nerves support the notion that an allergic mechanism is operative in the PNS involvement (18). The spinal cord lesions in AM were also found to be eosinophilic inflammation, which is common to Churg-Strauss syndrome as well as atopic disorders involving other organs (1). It is thus possible that an allergic mechanism is involved in the CNS lesion for- 
mation in AM. We previously reported that MNM of unknown etiology without preceding bronchial asthma is also associated with hyperIgEaemia and mite antigen-specific IgE (9). Together with the present findings that subclinical PNS involvement was frequent in AM, this suggests that patients having an atopic constitution may tend to multifocally develop both CNS and PNS inflammation.

F-waves were frequently found to be abnormal in AM patients. The neuropathological examination of the spinal cord lesions in AM revealed that axons as well as myelin were destroyed by inflammation accompanied with infiltration of CD4positive T cells, CD8-positive T cells, B cells and eosinophils (5). Therefore, axonal neuropathy including radiculopathy may be explained partly by extension of inflammation to the roots and partly by multifocal vasculitic inflammation along with the peripheral nerves.

On the other hand, several AM patients with apparent CNS lesions showed a demyelinating pattern on the peripheral conduction study. We have recently shown that myelitis developed in the Th2 dominant condition in these patients (19), in which enhanced humoral immunity may induce autoantibody production against PNS as well as CNS myelins. Further study of autoantibody formation in these patients is now under way in our laboratory.

In summary, the present study revealed that subclinical peripheral neuropathy is frequent in patients with AM, and it suggests that both PNS and CNS are prone to be involved multifocal involvement in patients with atopic constitutions.

Acknowledgements: This work was supported in part by grants from the Ministry of Education, Science, Sports and Culture of Japan, a Neuroimmunological Disease Research Committee grant and a Research on Brain Science grant from the Ministry of Health and Welfare of Japan.

\section{References}

1) Rothe MJ, Grant-Kels JM. Atopic dermatitis: an update. J Am Acad Dermatol 35: 1-13, 1996.

2) Kira J, Yamasaki K, Kawano Y, Kobayashi T. Acute myelitis associated with hyperIgEemia and atopic dermatitis. J Neurol Sci 148: 199-203, 1997.
3) Kira J, Kawano Y, Horiuchi I, et al. Clinical, immunological and MRI features of myelitis with atopic dermatitis (atopic myelitis). J Neurol Sci 162: 56-61, 1999.

4) Kira J, Kawano Y, Yamasaki K, Tobimatsu S. Acute myelitis with hyperIgEaemia and mite antigen specific IgE: atopic myelitis. J Neurol Neurosurg Psychiatry 64: 676-679, 1998.

5) Kikuchi $\mathrm{H}$, Osoegawa $\mathrm{M}$, Ochi $\mathrm{H}$, et al. Spinal cord lesions of myelitis with hyperIgEemia and mite antigen specific IgE (atopic myelitis) manifest eosinophilic inflammation. J Neurol Sci 183: 73-78, 2001.

6) Leiferman KM, Ackerman SJ, Sampson HA, Haugen HS, Venencie PY, Gleich GJ. Dermal deposition of eosinophil-granule major basic protein in atopic dermatitis. Comparison with onchocerciasis. New Eng J Med 313: 282-285, 1985.

7) Hamid QA, Minshall EM. Molecular pathology of allergic disease: I: lower airway disease. J Allergy Clin Immunol 105: 20-36, 2000.

8) Christodoulopoulos P, Cameron L, Durham S, Hamid Q. Molecular pathology of allergic disease: II: upper airway disease. J Allergy Clin Immunol 105: 211-223, 2000.

9) Horiuchi I, Kawano Y, Yamasaki K, et al. Heightened IgE response to mite antigens in inflammatory neuropathies. J Neurol Sci 166: 77-80, 1999.

10) Poser CM, Paty DW, Scheinberg L, et al. New diagnostic criteria for multiple sclerosis: Guidelines for research protocols. Ann Neurol 13: 227 231, 1983

11) Kurtzke JF. Rating neurologic impairment in multiple sclerosis: an expanded disability status scale (EDSS). Neurology 33: 1444-1452, 1983.

12) Shefner JM, Carter JL, Krarup C. Peripheral sensory abnormalities in patients with multiple sclerosis. Muscle \& Nerve 15: 73-76, 1992.

13) Cornblath DR, Asbury A, Albers JW, et al. Research criteria for diagnosis of chronic inflammatory demyelinating polyneuropathy (CIDP). Report from an Ad Hoc Subcommittee of the American Academy of Neurology AIDS Task Force. Neurology 41: 617-618, 1991.

14) Suga R, Tobimatsu S, Kira J, Kato M. Motor and somatosensory evoked potential findings in HTLV-1 associated myelopathy. J Neurol Sci 167: 102-106, 1999.

15) Zee PC, Cohen BA, Walczak T, Jubelt B. Peripheral nervous system involvement in multiple sclerosis. Neurology 41: 457-460, 1991.

16) Rubin M, Karpati GK, Carpenter S. Combined central and peripheral myelinopathy. Neurology 37: 1287-1290, 1987.

17) Soter NA, Wasserman SI. Physical urticaria/angioedema: An experimental model of mast cell activation in humans. J Allergy Clin Immuno 66: 358-365, 1980.

18) Inoue $A$, Koh CS, Tsukada $N$, Yanagisawa N. Allergic granulomatous angiitis and peripheral nerve lesion. Intern Med 31: 989-993, 1992.

19) Horiuchi I, Kawano Y, Yamasaki K, et al. Th1 dominance in HAM/TSP and the optico-spinal form of multiple sclerosis versus $\mathrm{Th} 2$ dominance in mite-antigen-specific IgE myelitis. J Neurol Sci 172: 17-24, 2000. 